\title{
Application of Redox Indicator to Monitor Development of Mouse Embryos Cultured In Vitro
}

\author{
Masayuki KOBAYASHI'), Haruka SASAKI ${ }^{1)}$ and Kyoko OGASAWARA ${ }^{1)}$ \\ ${ }^{1)}$ Department of Biotechnology, Faculty of Bioresource Sciences, Akita Prefectural University, \\ Akita, Akita 010-0195, Japan
}

\begin{abstract}
Alamar Blue, an oxidation-reduction indicator, added to a culture medium is reduced in living cells as an intermediate electron acceptor in the mitochondrial electron transport system, so that the absorbance of alamar Blue at a specific wavelength changes with the progression of cell growth or the number of living cells. In order to rapidly and quantitatively evaluate the development of preimplantation mouse embryos cultured in vitro, a colorimetric assay with alamar Blue was applied. Two-cell embryos, obtained from CD-1 mice, were cultured in 4-well dishes with $1 \mathrm{ml}$ of Whitten's medium containing $3 \mathrm{mg} / \mathrm{ml}$ of bovine serum albumin, and then transferred to 96-well plates $(5,10$ or 20 embryos/well) with $100 \mu \mathrm{l}$ of Whitten's medium containing alamar Blue $(10 \%, \mathrm{v} / \mathrm{v})$ and $3 \mathrm{mg} / \mathrm{ml}$ of bovine serum albumin. First, the effect of alamar Blue on the development of mouse embryos was examined. Although alamar Blue strongly inhibited the subsequent preimplantation development of the late 2-cell embryos, it had no significant effect on that of the 4- to 8-cell embryos. Changes in the absorbance of alamar Blue, with the progression of embryonic development and the number of embryos per well, were then monitored at 24-h intervals by measuring the absorbance using a microtiter plate reader. When the development of the 4- to 8-cell embryos was evaluated by the alamar Blue assay, the method required only 5-20 embryos per well of a 96-well plate and allowed daily monitoring of the proliferation for a period of $72 \mathrm{~h}$, without compromising the sterility of the cultures. The absorbance of alamar Blue changed with the progression of embryonic development and correlated with the number of embryos per well. The stimulatory effect of EDTA on the development of zygotes obtained from CD-1 ( 5 or 10 embryos/well) was also determined by this method. The results indicate that the assay is useful for quantifying the development of mouse embryos cultured in vitro.
\end{abstract}

Key words: Embryo, Development, Quantification, Redox indicator, Alamar Blue

(J. Reprod. Dev. 47: 113-118, 2001)

$\mathbf{T}$ he preimplantation development of mammalian embryos has been assessed based on morphological differences and classified into specific developmental stages. However, quantitative analyses reflecting the cell number, quality, and developmental potential of the embryos are required for a detailed examination of the effects of growth regulators on embryonic

Accepted for publication: December 20, 2000

Correspondence: M. Kobayashi development. Numerous quantitative assays have been used to monitor the proliferation and survival of somatic cells. These include: (i) the incorporation of radioactive nucleotides [1]; (ii) the cleavage of tetrazolium salts, MTT (3-[4,5-dimethylthiazol-2yl]-2,5-diphenyl tetrazolium bromide) [2] and XTT (sodium 3'-[1-(phenylamino-carbonyl)-3,4tetrazolium]-bis(4-methoxy-6-nitro)benzenesulfonic acid hydrate) [3]; and (iii) the incorporation of 5-bromodeoxyuridine, a pyrimidine analog [4]. But these assays are labor 
intensive and require the use of radioactive or toxic reagents. Furthermore, these assays require fixation or solubilization of the cells, and thus a determination of the kinetics of cell growth and other analyses cannot be performed with the same samples.

Recently, a simple, sensitive assay for quantifying the growth of somatic cells has been reported [5]. This assay uses a commercially available dye, alamar Blue, which is an oxidationreduction (Redox) indicator with a visible color change in response to the chemical reduction of the growth medium by living cells [6]. Alamar Blue acts as an intermediate electron acceptor in the mitochondrial electron transport system between the final reduction of $\mathrm{O}_{2}$ and cytochrome oxidase, and can be substituted for molecular oxygen for most oxidoreductases that can use molecular oxygen as an electron transporter [6]. Therefore, the absorbance of alamar Blue at a specific wavelength changes with a reduction in the mitochondrial electron transport system. Since the reduced form of alamar Blue is stable in the growth medium [5], it is accumulated in the medium as cell growth progresses. In the present study we examined the usefulness of alamar Blue in monitoring the development of mouse embryos cultured in vitro.

\section{Materials and Methods}

\section{Embryo collection and culture}

Preimplantation mouse embryos were obtained as follows. One-cell and 2-cell (the late 2-cell stage) embryos were obtained from pregnant mare serum gonadotrophin/human chorionic gonadotrophintreated CD-1 mice $[7,8]$.

The 1-cell embryos were cultured to the 4- to 8cell stage in $1 \mathrm{ml}$ of modified Whitten's medium (WM) [9] containing $3 \mathrm{mg} / \mathrm{ml}$ bovine serum albumin (BSA) with (+EDTA) or without $50 \mu \mathrm{M}$ EDTA in 4-well dishes at $37 \mathrm{C}$ in air containing 5\% $\mathrm{CO}_{2}$. The late 2-cell embryos were cultured to the 4to 8 -cell stage in $1 \mathrm{ml}$ of WM containing $3 \mathrm{mg} / \mathrm{ml}$ BSA in 4-well dishes at $37 \mathrm{C}$ in air containing $5 \%$ $\mathrm{CO}_{2}$.

\section{Alamar Blue assay}

WM containing $3 \mathrm{mg} / \mathrm{ml}$ BSA and $10 \%$ alamar Blue (ab; v/v, Alamar Biosciences, Inc.,
Sacramento, CA, USA) in the presence $(\mathrm{abWM}+\mathrm{EDTA})$ or absence $(\mathrm{abWM})$ of $50 \mu \mathrm{M}$ EDTA was prepared according to the manufacturer's instructions. The embryos were then transferred to 96 -well plates $(5,10$ or 20 embryos/well) with $100 \mu \mathrm{l}$ of abWM (for the non EDTA-treated embryos), or abWM+EDTA (for the EDTA-treated embryos), and were cultured at $37 \mathrm{C}$ in air containing $5 \% \mathrm{CO}_{2}$. Changes in the absorbance of alamar Blue, with progression of the development of the embryos, were monitored at 24$\mathrm{h}$ intervals by measuring the absorbance at $570 \mathrm{~nm}$ and $595 \mathrm{~nm}$ with a microtiter plate reader (model 550, Bio-Rad, Hercules, CA, USA). A subtraction analysis (O.D.570-O.D.595) of the dual wavelength measurements was performed to provide an accurate quantification of the reduced and oxidized forms of alamar Blue, and to reduce well-to-well variations. The wells containing $100 \mu \mathrm{l}$ of abWM or abWM+EDTA without embryos served as the background controls. Microscopic observation of the embryo development was also carried out. Embryos without shrunken, darkened, granular or fragmented blastomeres were classified as normal. The plates were then returned to the incubator until the next use.

\section{Statistical analysis}

The data were compared according to the percentage of embryos that reached normal developmental parameters and were analyzed by the chi-square test. The statistical significance of the differences between sample means was determined by the two-tailed Student's $t$ test or Cochran-Cox test, following Bartlett's test for uniformity of variances.

\section{Results and Discussion}

\section{Effect of alamar Blue on the preimplantation} development of mouse embryos cultured in vitro

In the first step in the evaluation of the alamar Blue assay, we examined the effect of alamar Blue on the development of preimplantation mouse embryos. No apparent effect of alamar Blue was observed on the subsequent development of 4- to 8cell embryos cultured under the conditions of 5, 10 or 20 embryos/well (Table 1). Similar experiments were conducted on the late 2-cell embryos. More than $73-85 \%$ of the late 2 -cell embryos, obtained 
Table 1. Effect of alamar Blue on morphological development of CD-1 4- to 8-cell embryos cultured in vitro

\begin{tabular}{lcccc}
\hline \multirow{2}{*}{$\begin{array}{l}\text { Culture } \\
\text { medium }\end{array}$} & $\begin{array}{c}\text { No. of embryos } \\
\text { / well }\end{array}$ & $\begin{array}{c}\text { No. of embryos } \\
\text { cultured }\end{array}$ & $\begin{array}{c}\text { No. (\%) of embryos that reached normal } \\
\text { developmental stages after culture with alamar Blue }\end{array}$ \\
\cline { 4 - 5 } & 5 & 70 & morula (24 h) & blastocyst (72 h) \\
WM & 5 & 70 & $69(98.6)$ & $56(80.0)$ \\
abWM & 10 & 110 & $64(91.4)$ & $46(65.7)$ \\
WM & 10 & 170 & $88(80.0)$ & $80(72.7)$ \\
abWM & 20 & 140 & $153(90.0)^{*}$ & $113(66.5)$ \\
WM & 20 & 140 & $138(98.6)$ & $110(85.7)$ \\
abWM & 5 & $133(95.0)$ & $110(78.6)$ \\
\hline
\end{tabular}

a CD-1 4- to 8-cell embryos developed from 2-cell embryos were transferred to modified Whitten's medium containing $3 \mathrm{mg} / \mathrm{ml} \mathrm{BSA}$ with (abWM) or without (WM) 10\% alamar Blue (ab, v/v). Five to 7 separate experiments were performed per group. * Significantly different from the WM value within the same number of embryos per well $(\mathrm{p}<0.05)$.

from a 2-cell blocking strain CD-1, were able to develop to the blastocyst stage in the absence of alamar Blue (Table 1), but the development of these noticeably decreased in the presence of alamar Blue. In our preliminary experiments (10 embryos / well), the rate of development to the blastocyst stage was significantly repressed $(\mathrm{p}<0.001)$ from $77 \%(77 / 100)$ to $37 \%(41 / 110)$ by alamar Blue. In order to clarify the detrimental effect of alamar Blue, we confirmed the effect on the development of late 2-cell embryos obtained from a non-blocking strain B6C3F1 (data not shown). The developmental stage-dependent effect of alamar Blue was also noted in this non-blocking strain. Only $41 \%(41 / 100)$ of the 2-cell embryos obtained from B6C3F1 developed to the blastocyst stage in the presence of alamar Blue [10 embryos/well, the control WM; 72\% (72/100), $\mathrm{p}<0.001]$. In contrast $57 \%(57 / 100)$ of the 8 -cell embryos obtained from B6C3F1 developed to the blastocyst stage even in the presence of alamar Blue [10 embryos/well, the control WM; 73\% (66/90), $p>0.05]$. These results indicate that alamar Blue inhibits the development of 2-cell embryos, regardless of the strains of mice, and that it is useful for the measurement of mitochondrial oxidation-reduction reactions during the subsequent development of 4- to 8-cell embryos cultured in vitro.

We conducted preliminary tests of another assay system with the tetrazolium salt WST-1 (Premix WST-1, Takara Shuzo Co., Kyoto, Japan), but development of the preimplantation CD-1 embryos at all stages was immediately and potently inhibited by this reagent.

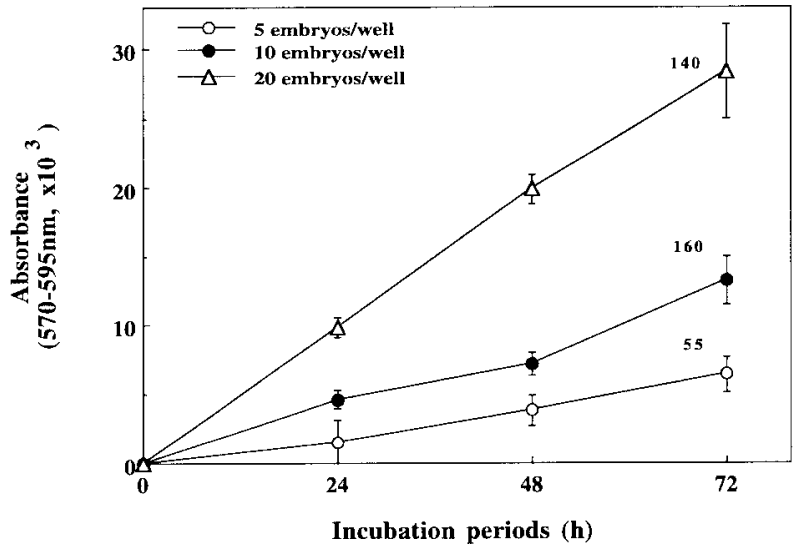

Fig. 1. Time-dependent changes in absorbance of alamar Blue during development of 4- to 8-cell embryos cultured in vitro. Four to 8-cell embryos developed in vitro from 2-cell embryos were transferred to each well of a 96-well plate $(5,10$ or 20 embryos/well), and cultured in $100 \mu \mathrm{l}$ of modified Whitten's medium containing $3 \mathrm{mg} / \mathrm{ml}$ BSA and $10 \%$ alamar Blue $(\mathrm{v} / \mathrm{v})$ at $37 \mathrm{C}$ in air containing $5 \% \mathrm{CO}_{2}$. The absorbance of alamar Blue was measured and a subtraction analysis (O.D.570-O.D.595) of the dual wavelength measurements was performed. The data are expressed as the mean \pm SE. The number of embryos cultured in each group is indicated inside the figure. Four to 6 separate experiments were performed for each experimental condition (5, 10 or 20 embryos/ well).

\section{Correlation between the number of embryos and alamar Blue absorbance}

In the second step in the evaluation of the alamar Blue assay, the correlation between the number of embryos and alamar Blue absorbance was examined in 4- to 8-cell embryos. Figure 1 shows the time-dependent changes in the absorbance of 
Table 2. Effect of EDTA on morphological development of CD-1 zygotes in the presence of alamar Blue from the 4- to 8-cell stage

\begin{tabular}{lcccc}
\hline \multirow{2}{*}{$\begin{array}{l}\text { Culture } \\
\text { medium }\end{array}$} & $\begin{array}{c}\text { No. of embryos } \\
\text { /well }\end{array}$ & $\begin{array}{c}\text { No. of embryos } \\
\text { cultured }\end{array}$ & $\begin{array}{c}\text { No. (\%) of embryos that reached normal } \\
\text { developmental stages after culture with alamar Blue }\end{array}$ \\
\cline { 4 - 5 } & 5 & 40 & morula (24 h) & blastocyst (72 h) \\
\hline abWM & 5 & 40 & $31(77.5)$ & $21(52.5)$ \\
abWM+EDTA & 10 & 140 & $38(95.0)^{*}$ & $32(80.0)^{*}$ \\
abWM & 10 & 150 & $113(80.7)$ & $36(25.7)$ \\
abWM+EDTA & & $139(92.7)^{* *}$ & $72(48.0)^{* * *}$ \\
\hline
\end{tabular}

${ }^{\text {a }} \mathrm{CD}$-1 4- to 8-cell embryos developed from zygotes in the presence or absence of $50 \mu \mathrm{M}$ EDTA were transferred to modified Whitten's medium containing $3 \mathrm{mg} / \mathrm{ml}$ BSA and 10\% alamar Blue (ab, v/v) with (abWM+EDTA) or without (abWM) $50 \mu \mathrm{M}$ EDTA. Four to 8 separate experiments were conducted. * Significantly different from the abWM value within the same number of embryos per well $(\mathrm{p}<0.05) .{ }^{* *}$ Significantly different from the abWM value within the same number of embryos per well $(\mathrm{p}<0.01)$. ${ }^{* *}$ Significantly different from the abWM value within the same number of embryos per well $(\mathrm{p}<0.001)$.

alamar Blue, during the course of development of the 4- to 8-cell embryos. Absorbance correlated with the progression of development of the 4- to 8cell embryos, when they were cultured under the condition of 5, 10 or 20 embryos/well.

It has been reported that because a linear relationship between alamar Blue absorbance and the number of living cells is found in 14 somatic cell lines [10], it is probable that the changes in absorbance of alamar Blue observed in our present study reflect the changes in the number of living cells in the embryos per well.

\section{Quantification, with alamar Blue, of the stimulatory} effect of EDTA on the development of CD-1 zygotes

Most of the zygotes obtained from the outbred strains, including CD-1 mice, are not able to develop to blastocysts when cultured in a chemically defined medium [11]. However, as first reported by Abramczuk et al. [12], EDTA at low concentrations $(10-50 \mu \mathrm{M})$ is an embryotrophic factor in the development of CD-1 zygotes cultured in vitro. We therefore attempted to evaluate the effect of EDTA treatment, from the 1-cell stage to the blastocyst stage, on the development of zygotes obtained from CD-1 by using alamar Blue (Table 2). In this experiment, the 4- to 8-cell embryos, precultured with WM+EDTA from the 1-cell stage, were further cultured with abWM+EDTA for $72 \mathrm{~h}$. Other embryos, precultured with WM, were further cultured with abWM for $72 \mathrm{~h}$. The development of the zygotes obtained from CD-1 was also stimulated by EDTA treatment even in the presence of alamar Blue. Although the rate of development of the CD-1 zygotes to blastocysts was low (about
$25-50 \%$ ) after $72 \mathrm{~h}$ in the absence of EDTA (abWM), it was significantly increased to $50-80 \%$ by culturing them with abWM+EDTA. Under these conditions, changes in the absorbance of alamar Blue were measured (Fig. 2). As the reduced form of alamar Blue is stable in the growth medium [5], the absorbance of alamar Blue at a specific wavelength increased with the progression of embryo growth in all the experimental groups. Under these conditions, the positive effects of the EDTA treatment on the development of embryos were detected with alamar Blue. Under both culture conditions (5 and 10 embryos/well), the absorbance of abWM+EDTA significantly increased 1.4-1.7-fold, compared with that of abWM after a 72-h culture. Although the rate of development of the embryos cultured under the condition of 5 embryos/well was $\sim 2$-fold higher than that of the embryos cultured under the condition of 10 embryos/well (Table 2), the absorbance of alamar Blue correlated with the number of embryos per well (Fig. 2). We consider that alamar Blue is also reduced by living cells in degenerated or growth-retarded embryos. Alamar Blue assay could therefore measure the potential for development of embryos.

In the present study alamar Blue was found to be harmful to mouse 2-cell embryos, but the assay is thought to be useful for quantifying the development of mouse embryos cultured in vitro. The same number of embryos (5 or 10 embryos/ well) gave different absorbance readings depending on the stage of the embryo development and the presence of EDTA. This suggests that the different absorbance readings reflect the number of 


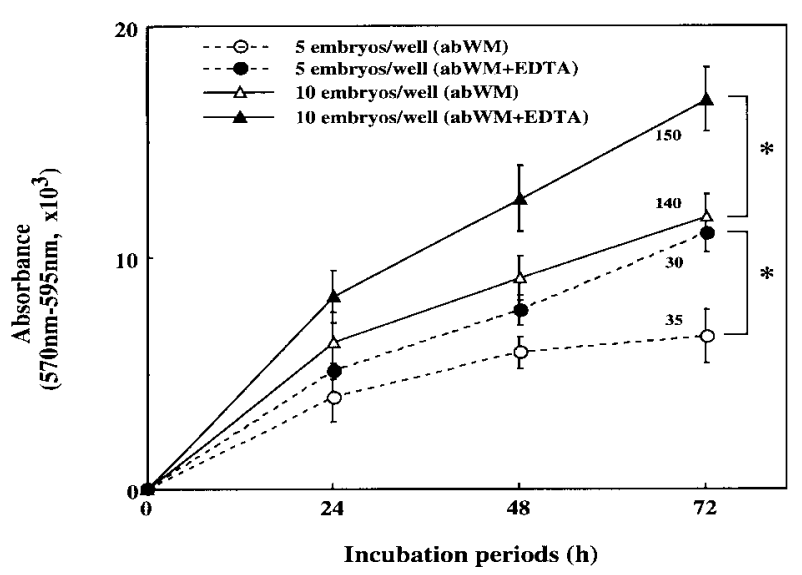

Fig. 2. Quantification with alamar Blue of stimulatory effect of EDTA on development of zygotes. Four to 8-cell embryos, developed in vitro from zygotes in the presence or absence of $50 \mu \mathrm{M}$ EDTA, were transferred to each well of a 96 -well plate at 5 or 10 embryos/well, and further cultured in $100 \mu \mathrm{l}$ of modified Whitten's medium containing $3 \mathrm{mg} / \mathrm{ml}$ BSA and $10 \%$ alamar Blue (v/v) with (abWM+EDTA) or without (abWM) $50 \mu \mathrm{M}$ EDTA at $37 \mathrm{C}$ in air containing $5 \% \mathrm{CO}_{2}$. The embryos precultured in the presence of EDTA from the 1-cell stage were further cultured with abWM+EDTA. The absorbance of alamar Blue was measured and the data were processed as described in the legend to Fig. 1. The number of embryos cultured in each group is indicated inside the figure. Four to 8 separate experiments were performed. *Significantly different from the abWM value within the same number of embryos per well $(\mathrm{p}<0.05)$. living cells in embryos, or the potential for development of the embryos. In view of our findings, we consider that the combination of this assay with microscopic observation of embryo morphology, or other analyses, will provide more detailed information on the effects of growth regulators on embryo development.

\section{Acknowledgments}

We would like to thank Ms. K. Nagai for technical assistance. Part of this study was supported by a Grant-In-Aid to M. K. for Encouragement of Young Scientists from the Japan Society for the Promotion of Science, a Grant to M. K. for the Promotion of Biotechnology from Akita Prefecture, Japan, and by a Grant to M. K. for the Promotion of Scientific Research from the President of Akita Prefectural University, Japan.

\section{References}

1. Schlager SI, Adams AC. Use of dyes and radioisotopic markers in cytotoxicity tests. Methods Enzymol 1983; 93: 233-245.

2. Mosmann T. Rapid colorimetric assay for cellular growth and survival: application to proliferation and cytotoxicity assays. J Immunol Methods 1983; 65: $55-63$.

3. Roehm NW, Rodgers GH, Hatfield SM, Glasebrook AL. An improved colorimetric assay for cell proliferation and viability utilizing the tetrazolium salt XTT. I Immunol Methods 1991; 142: 257-265.

4. Huong PL, Kolk AH, Eggelte TA, Verstijnen CP, Gilis H, Hendriks JT. Measurement of antigen specific lymphocyte proliferation using 5-bromodeoxyuridine incorporation. An easy and low cost alternative to radioactive thymidine incorporation. $J$ Immunol Methods 1991; 140: 243-248.

5. Ahmed SA, Gogal RM, Walsh JE. A new rapid and simple non-radioactive assay to monitor and determine the proliferation of lymphocytes: an alternative to $\left[{ }^{3} \mathrm{H}\right]$ thymidine incorporation assay. $J$ Immunol Methods 1994; 170: 211-224.

6. Shahan TA, Siegel PD, Sorenson WG, Kuschner WG, Lewis DM. A sensitive new bioassay for tumor necrosis factor. J Immunol Methods 1994; 175: 181187.

7. Kobayashi M, Hirako M, Minato Y, Sasaki K, Horiuchi R, Domeki I. Rat hepatoma Reuber H-35 cells produce a 2-cell stage specific inhibitor of the cleavage of mouse embryos. Biol Reprod 1996; 54: 364-370.

8. Kobayashi M, Hirako M, Minato Y, Sasaki K, Horiuchi R, Domeki I. Rat hepatoma Reuber H-35 cells produce factors that promote the hatching of mouse embryos cultured in vitro. Biol Reprod 1997; 56: 1041-1049.

9. Hoppe P. Technique of fertilization in vitro. In: 
Dixon R (ed.), Reproductive Toxicology. New York: Raven Press; 1985: 191-199.

10. Nakayama GR, Caton MC, Nova MP, Parandoosh Z. Assessment of the Alamar Blue assay for cellular growth and viability in vitro. I Immunol Methods 1997; 204: 205-208.

11. Goddard MJ, Pratt HPM. Control of events during early cleavage of the mouse embryo: an analysis of the "2-cell block". J Embryol Exp Morph 1983; 73: 111133.

12. Abramczuk J, Solter D, Koprowski H. The beneficial effect of EDTA on development of mouse one-cell embryos in chemically defined medium. Dev Biol 1977; 61: 378-383. 